OPEN ACCESS

Edited by:

Mohamed M. Abdel-Daim, Suez Canal University, Egypt

Reviewed by:

Marta Chagas Monteiro, Universidade Federal do Pará, Brazil Eman Mehanna,

Suez Canal University, Egypt

*Correspondence: Jian Wang

wangjiansph@sina.com

Specialty section: This article was submitted to Inflammation Pharmacology,

a section of the journal

Frontiers in Pharmacology

Received: 11 August 2018 Accepted: 31 October 2018 Published: 12 December 2018

Citation:

Li Y, Kakkar R and Wang J (2018) In vivo and in vitro Approach to Anti-arthritic and Anti-inflammatory

Effect of Crocetin by Alteration of Nuclear Factor-E2-Related Factor 2/hem Oxygenase (HO)-1 and NF- $\kappa B$

Expression

Front. Pharmacol. 9:1341. doi: 10.3389/fphar.2018.01341

\section{In vivo and in vitro Approach to Anti-arthritic and Anti-inflammatory Effect of Crocetin by Alteration of Nuclear Factor-E2-Related Factor 2/hem Oxygenase (HO)-1 and NF- $\mathrm{B}$ Expression}

\author{
Yi Li', Rajat Kakkar² and Jian Wang ${ }^{1 *}$ \\ ${ }^{1}$ Department of Joint Surgery, Shandong Provincial Hospital Affiliated to Shandong University, Jinan, China, ${ }^{2}$ Chandrasheker
} College of Pharmacy, Allahabad, India

Crocetin (apo carotenoid dicarboxylic acid) is a common constituent of saffron. Its importance is well documented in Chinese medicine. Some studies have reported the inhibitory effect on inflammation in rats. The aim of the current experimental investigation to scrutinize the anti-inflammatory effect of Crocetin using the lipo polysaccharide (LPS) induced mouse macrophages (RAW 264.7) in vitro and complete Freund's adjuvantinduced arthritis model and to explore in vivo possible mechanism of action. RAW 264.7 macrophages were used for estimation of the effect of crocetin on the cyclooxygenase (COX-2), nitric oxide (NO)production, anti-inflammatory and along with pro-inflammatory cytokines such as tumor necrosis factor- $\alpha$ (TNF- $\alpha$ ), interleukin-1 $\beta$ (IL-1 $\beta)$, interleukin6 (IL-6), and interleukin-10 (IL-10). Single intraperitoneal injection of complete freund's adjuvant (CFA) was used to induce arthritis. The rats were divided into different group and received the oral administration of crocetin in a dose-dependent manner with indomethacin till 28 days. The paw edema and body weight was estimated at regular interval of time. The biochemical parameters, hematological and pro-inflammatory cytokines such as tumor necrosis factor receptor 1 (TNF-R1), IL-6, and IL-1 $\beta$, Vascular endothelial growth factor (VEGF); heme oxygenase-1/nuclear factor erythroid 2-related factor $2(\mathrm{HO}-1 / \mathrm{Nrf}-2)$ expression were estimated at end of the experimental study. Crocetin inhibited the COX-2 catalyzed prostaglandin $\left(\mathrm{PGE}_{2}\right)$ and inducible nitric oxide synthase catalyzed NO production on RAW 264.7. The paw edema and body weight was significantly $(P<0.001)$ modulated by the Crocetin in a dose-dependent manner. Crocetin treatment increased the level of red blood cells (RBC), hemoglobin ( $\mathrm{Hb})$ and decreased level of white blood cells (WBC), erythrocyte sedimentation rate (ESR), alkaline phosphatase (ALP), serum glutamic pyruvic transaminase (SGPT), and serum glutamic-oxaloacetic transaminase (SGOT) parameters, with reduction of TNF- $\alpha$, IL6 , and IL-1 $\beta$. The protective effect of crocetin was substantiated with a reduction in 
expression of IL-6, IL-1 $\beta$, VEGF, and TNF-R1, respectively. Crocetin also increased the $\mathrm{HO}-1 / \mathrm{Nrf}-2$ and decreased the nuclear factor kappa-B (NF-kB) mRNA, protein expression. On the basis of the result, we can conclude that the reduction of $\mathrm{HO}-1 / \mathrm{Nrf}-2$ expression, as well as inflammatory mediators, may be involved in the protective effect of Crocetin in the CFA model.

Keywords: crocetin, enzymatic hydrolysis, arthritis, RAW 264.7 macrophage, inflammation

\section{INTRODUCTION}

Various stimuli such as toxic pathogens, noxious chemical and mechanical agents play a significant role in the inflammatory reaction and create a situation of tissue damage and infection (Eng and Lee, 2003). Macrophages play a significant role in the expansion, resolution, and maintenance of inflammation (Xu et al., 2003). Various stimuli viz., bacterial endotoxin lipopolysaccharides (LPS), interferon gamma (IFN- $\gamma)$, extracellular matrix proteins, pro-inflammatory (IL-1 $\beta$, TNF- $\alpha$, and IL-6) and other chemical mediators (Pahan et al., 1998). During the inflammatory reaction, macrophages become secreted and activate due to release of an excessive amount of inflammatory mediators viz., IL- $1 \beta$, TNF- $\alpha$, and IL-6; that have been linked to the numerous inflammatory disease including rheumatoid arthritis, Crohn's disease, cancer, asthma, Alzheimer's disease, auto-immune pathologies, and psoriasis to name few (Kmieć, 2001).

Activation of few inflammatory enzymes including inducible nitric oxide synthetase (iNOS), cyclooxygenase (COX-2) and secretion of prostaglandin $\mathrm{E}_{2}\left(\mathrm{PGE}_{2}\right)$ from arachidonic acid, and have played a significant role in the expansion of oncogenesis and inflammatory reaction (Gungor et al., 2014). Rahman (2002), suggest that the inhibition of overproduction of inflammatory mediators such as TNF- $\alpha, \mathrm{PGE}_{2}$, NO, IL-1 $\beta$, and IL-6 (Park et al., 2013)with up-regulation of COX-2 and iNOS is an imperative target for the prevention and treatment of inflammation and its related complications (Esser et al., 2014).

Typically arthritis is considered as the common inflammatory disease of joint characterized by being restricted joint movement, pain, and inflammation of synovial membrane (Sellam and Berenbaum, 2010). Rheumatoid arthritis (RA) is one of the common chronic inflammatory conditions which persists over months or years in developed countries and affects the synovial joints, a common cause of deformity and disability (Scott et al., 2010; Walsh and McWilliams, 2012). Joints changes,

\footnotetext{
Abbreviations: ALP, Alkaline phosphatise; CAT, Catalase; CFA, Complete freund's adjuvant; COX-2, Cyclooxygenase; DMEM, Dulbecco's modified eagle's medium; DMSO, Dimethylsulfoxide; ESR, Erythrocytes sedimentation rate; FBS, Fetal bovine serum; GSH, Glutathione; Hb, hemoglobin; HO-1, Heme oxygenase- 1 ; IFN- $\gamma$, Interferon gamma; IL-1 $\beta=$ Interleukin-1 $\beta$; IL6, Interleukin-6; IL-10, Interleukin-10; iNOS, Nitric oxide synthetase; LPS, Lipopolysaccharides; MMPs, Metalloproteinases; MTT, 4,5-dimethylthiazol-2-yl)2,5-diphenyltetrazolium bromide; NF-kB, Nuclear factor kappa-B; $\mathrm{NO}, \mathrm{NaNO}_{2}$, Sodium nitrite; Nitric oxide; Nrf-2, Nuclear factor erythroid 2-related factor 2; $\mathrm{PGE}_{2}$, Prostaglandin; pNpp, p-nitrophenyl phosphate; RA, Rheumatoid arthritis; RBC, Red blood cells; SGOT, Serum glutamic-oxaloacetictransaminase; SGPT, Serum glutamicpyruvictransaminase; SOD, Superoxidase dismutase; TNF- $\alpha$, Tumornecorsis factor- $\alpha$; TNF-R1, Tumor necrosis factor receptor 1, VEGF, Vascular endothelial growth factor; WBC, White blood cells.
}

which probably characterize the autoimmune reaction, consisting of inflammatory reaction, erosion of bone, cartilage, and proliferation of synovial. The epidemiology study of arthritis showed the arthritis ratio between male and female is 3:1 and prevalence is in $1 \%$ world population (Scutellari and Orzincolo, 1998; Jimenez-Boj et al., 2005).

Anderson hadclaimed that the enhancement of hind paw edema during the adjuvant-induced infection in rats is paralleled and its due to up-regulation of lysosomal enzymes activities in that particular area (Tekieh et al., 2011). The abovediscussed enzymes are involved in the degradation of structural macromolecules in cartilage proteoglycans and connective tissue (Martel-Pelletier et al., 2008; Sindhu et al., 2012). They also induce the destruction of extracellular activity by enhancing the activity of lysosomal enzymes. Further, they destroy the cellular structures and may participate in tissue damage in RA (Kaur et al., 2012). Complete Freund's adjuvant (CFA) is considered as the most reliable model for estimation of an anti-arthritic drug. CFA containing Mycobacterium tuberculosis per milliliter sterile paraffin oil (Bhalekar et al., 2015; Kumar et al., 2015). CFA induced the acute inflammation is linked with mast cell activation, leukocyte infiltration and secretion of free radicals and cytokines in circulation. CFA induced rheumatoid arthritis (RA) characterized by rapid activation of macrophage and secretion of various enzymes into the circulation playing a significant role in the vascular destruction, fibrosis and tissue destruction over a period of time (Harford et al., 2011; Kasimanickam et al., 2014).

Researchers are in the opinion that macrophage-derived cytokines like TNF- $\alpha$, IL- 6 , and IL-1 $\beta$ are directly involved in every phase of inflammatory reactions linked with the pathogenesis of RA initiating from autoimmunity in periarticular phase to upholding joining tissue destruction and chronic inflammation of synovitis (Scott et al., 2010). As on date available treatment of RA is steroidal, non-steroidal and immunosuppressive drugs which are used to control the inflammation symptoms and pain, they are associated with various undesirable side effects. With these obstructions, the researcher focuses on their research on alternative therapies, such as herbal and herbal based drugs. Now, $80 \%$ of the World population used the plant-based drug for the effective treatment of pain associated with the RA (Sahoo et al., 2010; Mori et al., 2011; Boissier et al., 2012).

Crocetin (carotenoid) extracted from the saffron flower and its medicinal properties have been tested in Chinese medicine (Bhandari, 2015). Multiple studies have suggested the role of spices in the reduction of chemical inflammation in the rodent. Very rare studies suggest that the saffron also 
inhibit the expansion of inflammation in the mice (Festuccia et al., 2014; Bhandari, 2015). Glycoprotein considers as the important compound which is involved in the cellular function and play an important role in the surface properties of cells and also involved in the tumorigenesis inflammation and mediator of immunological specificity (Gutheil et al., 2012). The available literature suggests that the carbohydrate moieties of glycoproteins have been implicated in the movement of metabolites inside the cell membrane and also create a direct relationship between the tumorigenesis, inflammation, and glycoprotein (Gutheil et al., 2012; Festuccia et al., 2014; Bhandari, 2015). To our knowledge, this is the first attempt to scrutinize the anti-inflammatory effect of crocetin in LPS induced RAW 264.7 macrophages and CFA induced chronic inflammation.

\section{MATERIALS AND METHODS}

\section{Chemicals}

Fetal bovine serum (FBS), Dulbecco's modified eagle's medium (DMEM), streptomycin and penicillin were obtained from Sigma-Aldrich, United States Crocetin, MTT (4,5dimethylthiazol-2-yl)-2,5-diphenyltetrazolium bromide), LPS, Indomethacin, and dimethylsulfoxide (DMSO) were purchased from the Sigma-Aldrich, United States. QuantiTect SYBR Green and High capacity cDNA reverse transcription kits were purchased for real-time PCR. Monoclonal antibodies against p-NF-kB p65, NF-kB p65, iNOS, TNF- $\alpha$, COX-2, and RANKL were procured from the Cell Signaling Technology, Beverly, MA.

\section{In vitro Studies}

\section{Cell Culture}

RAW 264.7 macrophages cells were used for the in vitro activity. The cells were diluted to a density of $2 \times 10^{5}$ cells $/ \mathrm{mL}$ into the 6 flat bottom plates and incubated at $37^{\circ} \mathrm{C}$ for $24 \mathrm{~h}$ in $\mathrm{CO}_{2}(5 \%)$ environment. The cells were treated with the various dilution $(12.5,25,50,100,200$, and $400 \mu \mathrm{g} / \mathrm{mL}$, dissolved in media) of crocetin and incubated for $24 \mathrm{~h}$. After that, the cells were treated with the lipopolysaccharide (LPS) $(1 \mu \mathrm{g} / \mathrm{mL})$ and again incubated for $24 \mathrm{~h}$. The culture medium was collected for proinflammatory cytokines (IL- $1 \beta$, TNF- $\alpha$, and IL-6), prostaglandin$\mathrm{E}_{2}\left(\mathrm{PGE}_{2}\right)$, nitric oxide (NO) and anti-inflammatory cytokines (IL-10). DMEM medium (cells without the LPS and sample) and $1 \% \mu \mathrm{g} / \mathrm{mL}$ LPS (without cells) were used as the blank and positive controls, respectively (Heo et al., 2010).

\section{Estimation of Prostaglandin- $\mathrm{E}_{2}\left(\mathrm{PGE}_{2}\right)$}

Enzyme-linkedimmunosorbent assay (ELISA) was used for the estimation of prostaglandin-E (Cayman Co., Ann Arbor, MI, United States) concentration in LPS stimulated RAW 264.7 cells. Briefly, the samples and standards drug with dilution 1:100, were added into the 96 well plates, precoated with mouse IgG antibodies, additionally treated with alkaline phosphatase conjugated prostaglandin- $\mathrm{E}_{2}$ antibodies and incubated at $37^{\circ} \mathrm{C}$ on the plate shaker for $3 \mathrm{~h}$ (Yoon et al., 2009). After the incubation, the cells were washed with the buffer to remove excess reagent and pNpp (p-nitrophenyl phosphate) substrate $(200 \mu \mathrm{L})$ followed by addinto each well plate and incubated for $60 \mathrm{~min}$ $50 \mu \mathrm{L}$ was added to stop the reaction and the intensity of the yellow color was estimated immediately at multimode microplate reader at $405 \mathrm{~nm}$ and the concentration of $\mathrm{PGE}_{2}$ was determined via using the $\mathrm{PGE}_{2}$ standard curve (Zong et al., 2012).

\section{Estimation of Nitric Oxide (NO) Level}

Griess diazotization reaction was used for the estimation of the concentration of nitrite by the reported method of Bryan and Grisham (2007), with minor modification. Briefly, cell culture medium $(150 \mu \mathrm{L})$ was incubated with the equal quantity of Griess reagent $(0.1 \% \mathrm{~N}-1$-(naphthyl) ethylenediamine- dihydrochloride, $1 \%$ sulfanilamide in $2.5 \%$ phosphoric acid) at $37^{\circ} \mathrm{C}$ for $30 \mathrm{~min}$ and the absorbance was estimated at the $548 \mathrm{~nm}$. Sodium nitrite $\left(\mathrm{NaNO}_{2}\right)$ standard curve was used for the estimation of the concentration of nitrite in treated cells.

\section{Estimation of Inflammatory and Anti-inflammatory Cytokines}

The inflammatory cytokines (IL- $1 \beta$, TNF- $\alpha$, IL-6) and antiinflammatory cytokines (IL-10) levels were estimated in cell culture supernatant by kit as per the instruction of manufacture (Perpro Tech Inc., Rocky Hill, NJ, United States). Briefly, the samples including 1:50 for IL-6, 1:200 for TNF- $\alpha$ and pure sample for IL- $1 \beta$ and IL-10 were used for the analysis. The standard curves for IL- $1 \beta$, TNF- $\alpha$, IL-10, and IL- 6 were generated by standard curve plot.

\section{Estimation of COX-2 and iNOS}

For the estimation of iNOS and COX-2 inhibitory activity, RAW 264.7 cells procured from the American Type Culture Collection, and were harvested in DMEM supplement along with $1 \%$ antibiotics (streptomycin and penicillin) 10\% FBS under the $5 \% \mathrm{CO}_{2}$ at $37^{\circ} \mathrm{C}$, the cells were activated LPS method with minor modification. Briefly, 96 well plates were used for incubation of cells. After pre-incubation, the test samples and LPS were added to these cells and incubated for the next $24 \mathrm{~h}$. Test compound dissolved in DMSO and diluted with serum-free DMEM for appropriate concentrations and DMSO was used to for adjusting the final concentration $0.1 \%(\mathrm{v} / \mathrm{v})$. Further, MTT assay was performed for the estimation of cell viability (Chen et al., 2008; Zong et al., 2012).

\section{Animals}

Swiss albino Wistar rats (100-125 g) were used in our experimental study. The rats were obtained from the central animal house and were kept in the standard condition (single polypropylene cage) (temperature $25 \pm 2$; relative humidity 60-80 and 12/12 $\mathrm{h}$ dark/light cycle). The animals received the standard pellet diet and water ad libitum. This study was approved by the Institutional Animal Ethical Committee (CS/2017/278/02).

\section{Experimental Study CFA Induced Chronic Inflammation Model}

The rats were divided into 6 groups and with 10 rats in each group in the following set. 
Group I: Normal control treated with saline only

Group II: Normal control received crocetin $(20 \mathrm{mg} / \mathrm{kg})$

Group III: Arthritis control received saline only

Group IV: Arthritis and treated with crocetin $(5 \mathrm{mg} / \mathrm{kg})$

Group V: Arthritis and treated with crocetin $(10 \mathrm{mg} / \mathrm{kg})$

Group VI: Arthritis and treated with crocetin $(20 \mathrm{mg} / \mathrm{kg})$

Group VII: Arthritis and treated with indomethacin (10 mg/kg)

All group rats received the single intradermal injection of CFA $(0.5 \% \mathrm{w} / \mathrm{v})$ and received the oral treatment of crocetin for 28 days except Groups I and II (Kumar et al., 2016). The hind paw joint diameters and body weight were estimated at regular interval. After completion of the protocol, the blood samples were collected and sacrificed for histopathology (Kuroki et al., 2011; Randell and Daneshtalab, 2016).

\section{Evaluation of the Arthritis Index}

Kumar et al. (2016), a published method was used for the estimation of the arthritis index via minor modification. The arthritis index estimated on the visual scoring system. We use the scale $0-4$, scale 0 : unchanged, scale 1 erythema of limb and mild swelling, scale 2: erythema of limb and moderate swelling: score 3: erythema of lib and coarse swelling and score 4: the inability of limb and gross deformity. The visual score total more than 1 suggest arthritis and maximum score reach 16.

\section{Sample Preparations}

For the estimation of different biochemical parameters, the rats were anesthetized at the end of the experimental study and blood samples were collected via puncturing the retro-orbital plexus. The blood samples were centrifuged at $10,000 \mathrm{rpm}$ for $10 \mathrm{~min}$ to collect the serum for estimation the different parameters.

\section{Hematological Parameters}

The collected blood samples further used for the estimation of red blood cells (RBC), white blood cells (WBC), erythrocytes sedimentation rate (ESR), and hemoglobin ( $\mathrm{Hb})$, via using the published method (Kaithwas and Majumdar, 2010; Kaithwas et al., 2012; Gautam et al., 2016).

\section{Biochemical Parameters}

Hepatic parameters such as alkaline phosphatise (ALP), serum glutamic pyruvic transaminase (SGPT), and serum glutamicoxaloacetic transaminase (SGOT) were estimated via using the available kits (Span Diagnostic Reagent Kit, India) via using the manufacture instruction.

\section{Antioxidant Parameters}

Antioxidant parameters including glutathione (GSH), catalase (CAT), and superoxide dismutase (SOD) were estimated as per the user manual of standard kits (Sigma-Aldrich, St. Louis, MO, United States).

\section{Quantitative Real-Time PCR Determination}

Trizol reagent (Sigma-Aldrich, St. Louis, MO, United States) was used for the extraction of total RNA from the paw tissue of CFA induced arthritic rats and UV spectrophotometer was used for the estimation the concentration of Isolated RNA followed by gel electrophoresis was used for the determination of cDNA synthesis via using the RevertAid First Strand cDNA synthesis kit (Thermo Scientific Scientific, Waltham, MA, United States). The primers for real-time PCR were designed from the individual mRNA transcript via using Primer 3 input. Nrf-2 (F-G CCTTCCTCTGCTGCCATTAGT, R-TCGGCTGGGACTTGT GTTCAGT), HO-1 (F-ACCCCACCAAGTTCAAACAGC, RCCTCTGGCGAAGAAACTCTGTC), GAPDH (F-TGGAAGA TGGTGATGGGTTT, R-AGACAGCCGCATCTTCTTGT), and NF-кB (F-TTCTGGTGCATTCTGACCTTGC, R-GAGGAAG GCTGTGAACATGAGG). SYBR Green PCR Master Mix was performed for real-time quantitative PCR via using the manufacture instruction. The fold changes in the gene expression levels of targeted genes were estimated with normalization of GAPDH values and each gene estimation performed in triplicates.

\section{Statistical Analysis}

Different between the groups were estimated via using the oneway analysis of variance (ANOVA) using the GraphPad Prism 7 software for the window. All the data are presented with the S.E.M and post hoc testing was performed for inter-group comparisons using the significant difference. Where $P$-values such as $p<0.05, p<0.01$, and $p<0.001$ are considered as significant.

\section{RESULTS}

\section{Effect of Crocetin on the Cell Viability of RAW 264.7 Macrophages}

Figure 1 are presents the effect of the crocetin on the cytotoxicity of RAW 267.4 macrophages. MTT assay was used to scrutinize the cell viability on RAW 267.4 macrophages. The result from Figure 1 clearly exhibits that the different concentration of crocetin $(12.5-400 \mu \mathrm{g} / \mathrm{mL})$ did not demonstrate any cytotoxic effect on RAW 267.4 cells.

\section{Effect of Crocetin on Phagocytic Activity of RAW 264.7 Cells}

Neutral red uptake assay was used to estimation the phagocytic activity of crocetin on RAW 267.4 cells. Figure 1B revealed that the crocetin treated cells significantly $(P<0.001)$ boosted the phagocytic activity on RAW 267.4 cells as a compared to the untreated cells. Figure 1B clearly showed that the lower dose of crocetin $(12.5 \mu \mathrm{g} / \mathrm{mL})$ significantly $(P<0.001)$ excited the phagocytosis, on the other hand, higher dose of crocetin did not show much effect on the phagocytosis in RAW 267.4 cells.

\section{Effect of Crocetin on NO Production}

Figure 1C demonstrated the effect of crocetin on the NO production on LPS induced RAW 267.4 cells. Figure 1C showed that the minimum amount of NO was release when macrophages were alone cultured and LPS stimulated the macrophages NO production 

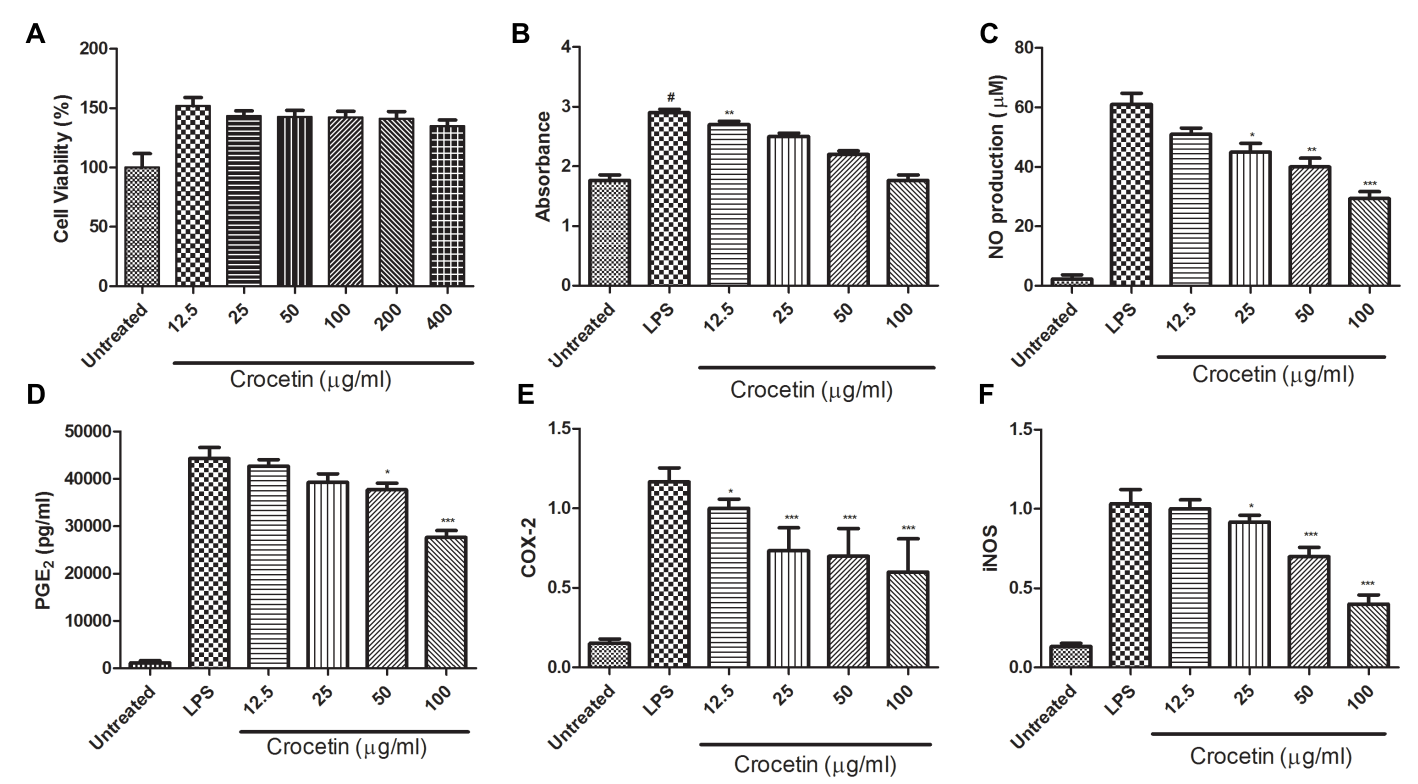

FIGURE 1 | (A) Showed the effect of crocetin on viability of RAW 264.7 macrophages. (B) Showed the effect of crocetin on phagocytic activity of RAW 264.7 macrophages, (C) showed the effect of crocetin on NO production of RAW 264.7 macrophages, (D) showed the effect of crocetin on PGE 2 of RAW 264.7 macrophages, (E) showed the effect of crocetin on COX-2 production of RAW 264.7 macrophages and (F) showed the effect of crocetin on iNOS production of RAW 264.7 macrophages. The data are presented as mean \pm SEM. No significant significance was found in the control and treated groups as scrutinized via one way ANOVA with Dunnett'sposthoc test and designated as ${ }^{*} p<0.05,{ }^{* *} p<0.01,{ }^{* * *} p<0.001$. ${ }^{*} p<0.05$ indicates the difference between the control and the LPS-treated group.

$(61 \pm 5.46 \mu \mathrm{M})$. On the other hand, crocetin $(100 \mu \mathrm{g} / \mathrm{mL})$ significantly $(P<0.001)$ reduced the production of $\mathrm{NO}$ $(29.73 \pm 4.56 \mu \mathrm{M})$ as a compared to LPS control. Crocetin $(12.5 \mu \mathrm{g} / \mathrm{mL})$ alter the production of $\mathrm{NO}$ but the data was not significant.

\section{Effect of Crocetin on $\mathrm{PGE}_{2}$ Production}

Figure 1D revealed that the LPS induced macrophages increased the production of $\mathrm{PGE}_{2}$ up to $(44,374 \pm 1244 \mathrm{pg} / \mathrm{mL})$ when compared to untreated cells and crocetin significantly $(P<0.001)$ down-regulated the $\mathrm{PGE}_{2}$ production in LPS induced macrophages at a dose of $100 \mu \mathrm{g} / \mathrm{mL}$.

\section{Effect of Crocetin on COX-2 and iNOS}

During the inflammation, the level of COX-2 and iNOS was boosted and increased inflammatory reaction was observed. The same momentum was observed in our experimental study. LPS induced macrophages group showed the increased level of COX-2 and iNOS as compared to untreated cells and dose-dependent treatment of crocetin significantly $(P<0.001)$ down-regulated the COX-2 level as compared to LPS induced macrophages group (Figure 1E).

Similar results were observed in the iNOS concentration. LPS induced group macrophages exhibited the increased concentration and by dose-dependent treatment of crocetin reduced the iNOS concentration in LPS induced macrophages (Figure 1F).

\section{Effect of Crocetin on Pro-inflammatory Cytokines}

During the inflammation, a lot of pro-inflammatory mediator such as (IL-1 $\beta$, IL-6, and TNF- $\alpha$ ) and inflammatory mediator IL10 are boosted and start the expansion of inflammation reaction. The same result was observed in our experimental study. Figure 2 exhibited the increased level of IL-1 $\beta(27 \pm 2.85 \mathrm{pg} / \mathrm{mL})$, IL$6(9004 \pm 753 \mathrm{pg} / \mathrm{mL})$, TNF- $\alpha(27,695 \pm 1203 \mathrm{pg} / \mathrm{mL})$ and IL-10 $(616.75 \pm 11.56 \mathrm{pg} / \mathrm{mL})$ and crocetin $(100 \mu \mathrm{g} / \mathrm{mL})$ significantly $(P<0.001)$ down-regulated the level of IL-1 $\beta$ $(14.9 \pm 2.67 \mathrm{pg} / \mathrm{mL})$, IL-6 (3187 $\pm 578 \mathrm{pg} / \mathrm{mL})$ and TNF- $\alpha$ $(15,004 \pm 936 \mathrm{pg} / \mathrm{mL})$ and IL-10 $(104.6 \pm 7.64 \mathrm{pg} / \mathrm{mL})$ at end of the experimental study (Figure 2).

\section{Effect on the Body Weight}

Table 1 showed the effect on the body weight of all group rats. CFA induced group rats showed the reduced body weight at end of the experimental study and dose-dependent treatment of Crocetin showed significantly $(P<0.001)$ increased body weight at end of the experimental study. Indomethacin-induced group rats showed the increased body weight at end of the experimental study.

\section{Effect on Paw Edema}

CFA induced group rats showed the increased paw edema at end of the experimental study (Table 2). The paw edema increased after the 7 days induction of CFA induced arthritis, which further increased till 25 days and remain unchanged at end of the 

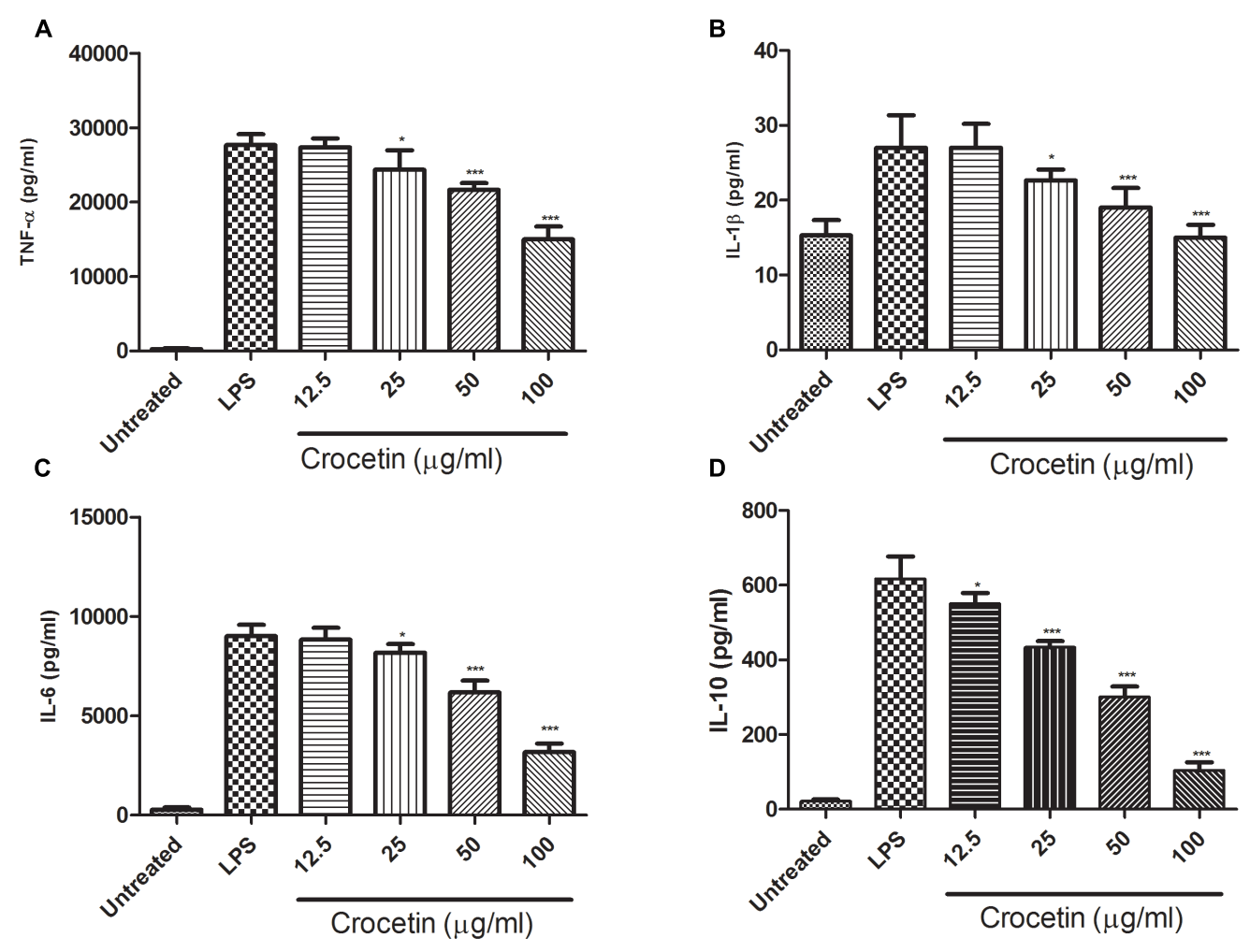

FIGURE 2 | Showed the effect of crocetin on proinflammatory and inflammatory mediators of RAW 264.7 macrophages. (A) TNF- $\alpha$, (B) IL-1 $\beta$, (C) IL-6, and (D) IL-10. The data are presented as mean \pm SEM. No significant significance was found in the control and treated groups as scrutinized via one way ANOVA with Dunnett's post hoc test and designated as ${ }^{*} p<0.05,{ }^{* *} p<0.01,{ }^{* * *} p<0.001$.

experimental study. Crocetin treatment showed the reduction in the paw edema after 14 days and also reduced the paw edema at end of the experimental study. Indomethacin-induced group rats showed the reduction of the paw edema at end of the experimental study.

\section{Effect on Arthritis Score}

Figure 3 exhibited the arthritis score of all group of rats except normal control and normal control treated with crocetin $(10 \mathrm{mg} / \mathrm{kg})$. Normal and normal control treated with crocetin $(10 \mathrm{mg} / \mathrm{kg})$ did not show any sign and symptom of arthritis. CFA induced group rats showed the arthritis score 15.3 at day 28 and confirm arthritis in this group rats. Dose-dependent treatment of crocetin significantly $(P<0.001)$ reduced the arthritis score of $12.6,7.9$, and 3.4 at a dose of $2.5,5$, and $10 \mathrm{mg} / \mathrm{kg}$. A similar result was observed in the indomethacin-treated group of rats.

\section{Effect on Antioxidant Parameters}

Figure 4 exhibits the antioxidant level of normal and CFA treated group rats. CFA induced group rats showed the reduced level of SOD, CAT, and GSH and dose-dependent treatment of crocetin significantly $(P<0.001)$ increased the

TABLE 1 | showed the effect of crocetin and indomethacin on body weight of normal and CFA induced arthritic rats.

\begin{tabular}{|c|c|c|c|c|c|c|}
\hline \multirow[t]{2}{*}{ S. No } & \multirow[t]{2}{*}{ Groups } & \multicolumn{5}{|c|}{ Time (Days) } \\
\hline & & Day 0 & Day 7 & Day 14 & Day 21 & Day 28 \\
\hline 1 & NC & $100 \pm 4.35$ & $109.34 \pm 5.43$ & $119.23 \pm 6.54$ & $130.83 \pm 7.94$ & $141.34 \pm 9.34$ \\
\hline 2 & $\mathrm{NC}+$ Crocetin (10 mg/kg) & $103.2 \pm 5.43$ & $113.45 \pm 6.94$ & $125.3 \pm 5.84$ & $136.34 \pm 6.78$ & $147.38 \pm 83$ \\
\hline 3 & CFA & $104.4 \pm 5.67$ & $101.3 \pm 6.54$ & $98.6 \pm 5.67$ & $96.4 \pm 6.47$ & $94.54 \pm 5.67$ \\
\hline 4 & CFA+Crocetin (2.5 mg/kg) & $105.54 \pm 6.76^{\mathrm{ns}}$ & $104.37 \pm 5.43^{*}$ & $102.45 \pm 5.93^{*}$ & $102.67 \pm 6.54^{* *}$ & $104.56 \pm 5.67^{* * *}$ \\
\hline 5 & CFA+Crocetin (5 mg/kg) & $103.83 \pm 5.83^{\mathrm{ns}}$ & $102.53 \pm 7.34^{*}$ & $105.45 \pm 6.54^{* *}$ & $106.52 \pm 5.67^{* * *}$ & $109.34 \pm 6.54^{* * *}$ \\
\hline 6 & CFA+Crocetin (10 mg/kg) & $103.45 \pm 5.67^{\mathrm{ns}}$ & $104.34 \pm 5.67^{*}$ & $111 \pm 5.78^{* * *}$ & $117.34 \pm 4.56^{* * *}$ & $125.67 \pm 5.63^{* * *}$ \\
\hline 7 & CFA+Indomethacin (10 mg/kg) & $103.92 \pm 4.78^{\mathrm{ns}}$ & $104.67 \pm 5.63^{*}$ & $112.34 \pm 5.78^{* * *}$ & $119.3 \pm 5.43^{* * *}$ & $126.43 \pm 6.56^{* * *}$ \\
\hline
\end{tabular}

All values are presented as mean \pm SEM. Statistical analysis by one-way ANOVA followed by post hoc multiple comparisons. ${ }^{*} p<0.05,{ }^{* *} p<0.01$, and ${ }^{* * *} p<0.001$. 


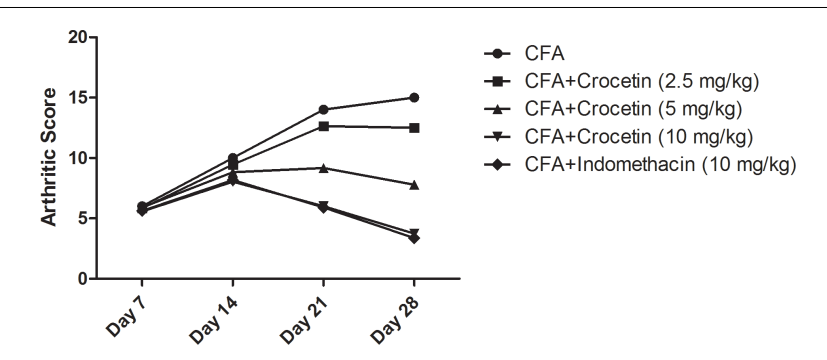

FIGURE 3 | Showed the arthritic score of crocetin and indomethacin on the normal and CFA induced arthritic rats. All values are presented as mean \pm SEM. Statistical analysis by one-way ANOVA followed by post hoc multiple comparisons.

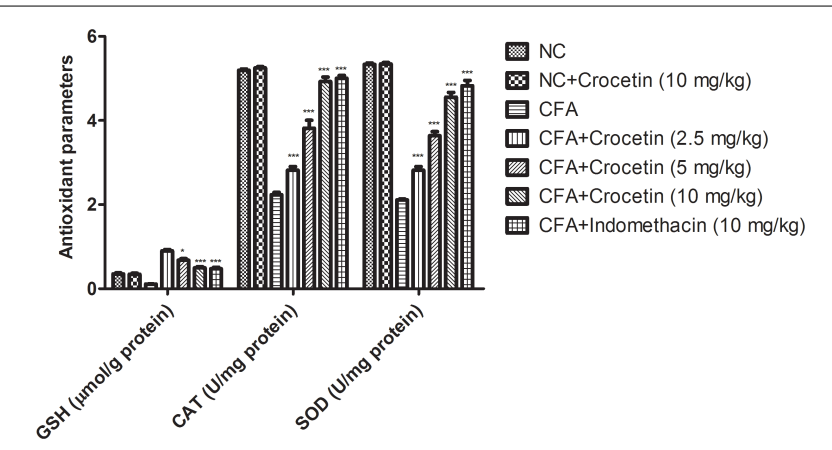

FIGURE 4 | Showed the effect of crocetin and indomethacin on the level of GSH, CAT and SOD on the normal and CFA induced arthritic rats. All values are presented as mean \pm SEM. Statistical analysis by one-way ANOVA followed by post hoc multiple comparisons. ${ }^{*} p<0.05,{ }^{* *} p<0.01$, and *** $p<0.001$

level of SOD, CAT, and GSH at end of the experimental study.

\section{Effect on Biochemical Parameters}

Figure 5 showed the level of ALT, AST, and ALP were significantly $(P<0.001)$ increased and the total protein level was significantly $(P<0.001)$ decreased in the CFA induced arthritis group rats. Crocetin treatment showed the significantly $(P<0.001)$ alteration of biochemical parameters in a dose-dependently

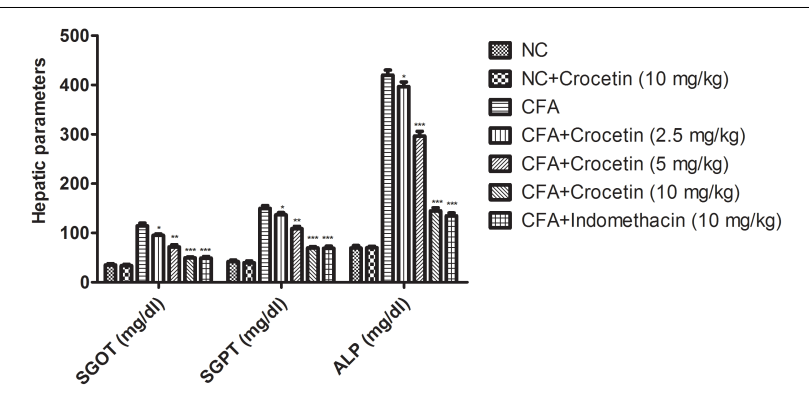

FIGURE 5 | Showed the effect of crocetin and indomethacin on the level of SGOT, ALP, and SGPT on the normal and CFA induced arthritic rats. All values are presented as mean \pm SEM. Statistical analysis by one-way ANOVA followed by post hoc multiple comparisons. ${ }^{*} p<0.05$, ${ }^{* *} p<0.01$, and $* * * p<0.001$.

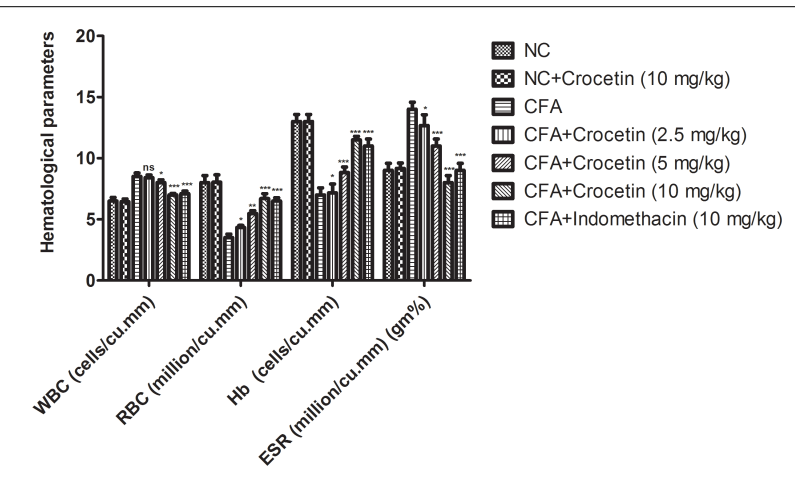

FIGURE 6 | showed the effect of crocetin and indomethacin on the level of $\mathrm{RBC}, \mathrm{WBC}, \mathrm{Hb}$ and ESR on the normal and CFA induced arthritic rats. All values are presented as mean \pm SEM. Statistical analysis by one-way ANOVA followed by post hoc multiple comparisons. ${ }^{*} p<0.05,{ }^{* *} p<0.01$, and $* * * p<0.001$.

manner. The same result was observed in the indomethacintreated group rats.

\section{Effect on Hematological Parameters}

Figure 6 showed the effect of Crocetin and indomethacinon the hematological parameters. CFA induced showed the reduced the level of RBC, $\mathrm{Hb}$ and enhanced level of WBC, ESR and in dose-dependent manner treatment of Crocetin significantly

TABLE 2 | showed the effect of crocetin and indomethacin on joint diameter of CFA induced arthritic rats.

\begin{tabular}{|c|c|c|c|c|c|}
\hline S. No & Groups & \multicolumn{4}{|c|}{ Joint diameter (mm) } \\
\hline 1 & CFA & $1.26 \pm 0.11$ & $1.16 \pm 0.15$ & $1.13 \pm 0.16$ & $1.03 \pm 0.12$ \\
\hline 3 & CFA+Crocetin (5 mg/kg) & $1.23 \pm 0.13^{\mathrm{ns}}$ & $0.96 \pm 0.11^{* * *}$ & $0.80 \pm 0.9^{* * *}$ & $0.5 \pm 0.7^{* * *}$ \\
\hline 4 & CFA+Crocetin (10 mg/kg) & $1.16 \pm 0.12^{\mathrm{ns}}$ & $0.8 \pm 0.09^{* * *}$ & $0.55 \pm 0.06^{* * *}$ & $0.26 \pm 0.02^{* * *}$ \\
\hline
\end{tabular}

$\mathrm{NC}$ and $\mathrm{NC}$ rats treated with crocetin $(10 \mathrm{mg} / \mathrm{kg})$ did not show any sign of increase joint diameter. 

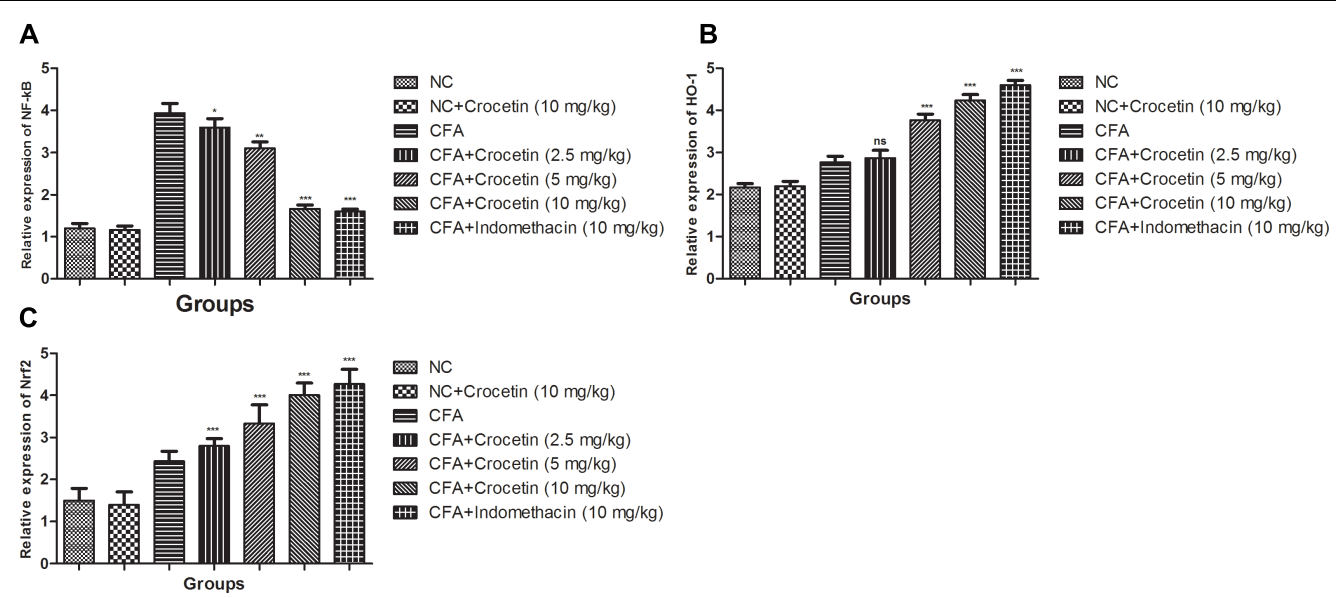

FIGURE 7 | Effect of crocetin and indomethacin on mRNA expression of (A) NF-kB, (B) HO-1, and (C) Nrf-2 in normal and CFA induced rats. All values are presented as mean \pm SEM. Statistical analysis by one-way ANOVA followed by post hoc multiple comparisons. ${ }^{*} p<0.05,{ }^{* *} p<0.01$, and ${ }^{* * *} p<0.001$.

$(P<0.001)$ reduced the level of WBC, ESR and increased the level of $\mathrm{RBC}, \mathrm{Hb}$ at end of the experimental study. A similar trend was observed in the indomethacin-induced group rats.

\section{Gene Expression Estimation via Real-Time PCR}

Figure 7 showed the mRNA expression levels of HO-1, Nrf2 , and NF- $\kappa \mathrm{B}$ of crocetin and indometacin treated group rats. A marked increased level of NF- $\kappa \mathrm{B}$ and reduced level of HO-1, Nrf-2 was observed in the CFA induced group rats and crocetin and indomethacin treatment showed the alteration in the gene expression of $\mathrm{HO}-1, \mathrm{Nrf}-2$, and NF- $\mathrm{B}$, respectively.

\section{DISCUSSION}

This study was an effort to scrutinize the anti-inflammatory effect of crocetin in in vitro and in vivo experimental model by LPS stimulated RAW 267.4 macrophages and CFA induced chronic arthritis model, respectively. Crocetin exhibited the inhibitory potential against the COX-2, iNOS, proinflammatory (IL-1 $\beta$, IL-6, IL-10, and TNF- $\alpha$ ) in in vitro assays, a potent in vivo potential in a rat model, suggested the protective and therapeutic effect on inflammatory tissue. Lipopolysaccharide (prototypical endotoxin) isolated from the Gram-negative bacterial membrane can directly activate the endothelial cells, macrophages and complement triggering generation of inflammatory mediators viz., COX-2, iNOS, pro-inflammatory (IL-1 $\beta$, IL-6, IL-10, and TNF- $\alpha$ ), respectively.

Excessive generation of NO, play a significant role in the provocation of chronic inflammatory and circulatory shock diseases, like inflammatory lung disease, septic shock, colitis and inflammatory hepatic dysfunctions (Zhang et al., 2017). Many of these disease conditions show the quick onset and expansion, frequently that result in the failure of conventional anti-inflammatory treatment with high mortality rates, a concurrent down-regulation of NO production pathways (Zhang et al., 2012), as exposed by crocetin may suggest managing the quick progression of inflammatory reactions. In vitro macrophages cell model or other cell lines model are very useful to study the high-level production of NO (Zhang et al., 2012). On the basis of the result, we can conclude that crocetin inhibits the LPS stimulate NO production via suppression of inflammatory expression including COX2 and iNOS (Figure 1). On the other hand, it was also scrutinized the cytotoxic effect of crocetin in RAW 267.4 macrophages by MTT assay that suggest that its minimum dose did not influence the viability of RAW 267.4 cells. Therefore, the suppression of LPS induced NO production via crocetin was not the result of a probable cytotoxic upshot on these cells.

For confirmation of $\mathrm{NO}$ and $\mathrm{PGE}_{2}$ inhibitory mechanism of Crocetin, it showed the significant inhibition of $\mathrm{PGE}_{2}$ and slight reduction of NO production. The current finding suggests that Crocetin directly down-regulated the COX-2 and also affected the iNOS production in a different way (Hseu et al., 2005; Yoon et al., 2009; Heo et al., 2012).

Various researchers suggest that the excessive generation of $\mathrm{PGE}_{2}$ and $\mathrm{NO}$ play a significant role in the provocation of chronic disease including pulmonary and hepatic dysfunction disease (Ohgami et al., 2003). Secretion of $\mathrm{PGE}_{2}$ and NO play an important role in the alteration of molecular mechanisms that regulate the $\mathrm{PGE}_{2}$ generation pathway (Heo et al., 2012). The available reports suggest that the generation of both $\mathrm{PGE}_{2}$ and $\mathrm{NO}$ was blocked via NOS inhibitors in RAW 267.4 macrophages cells, this suppressive effect was reverted via co-incubation with $\mathrm{NO}$ synthesis precursor (L-arginine) (Zhang et al., 2012). Therefore, reduction of iNOS via nonselective NOS inhibitors calmed the generation of $\mathrm{PGE}_{2}$ and NO simultaneously in LPS induced macrophages, suggesting the secretion of endogenous NO from the macrophages that exerted a stimulatory action on boosting the $\mathrm{PGE}_{2}$ production (Hseu et al., 2005; Yoon et al., 2009; Heo et al., 2012). On the 
contrary, activation of COX, turn into the alteration of the L-arginine-NO production pathway, whereas the suppression of COX down-regulate the NOS effect in human platelets. Our results are the outcome of cross-talk between $\mathrm{PGE}_{2}$ and $\mathrm{NO}$ pathways.

CFA induced RA model used for the estimation of pharmacology and pathophysiological control of inflammatory processes, as well as the, scrutinize the anti-arthritic effect of drugs. CFA induced RA showed the chronic inflammation, in the first 2-4 days induced the local inflammation and after that induced the chronic inflammation which remains for next few weeks (Bernardi et al., 2009; Rayhana et al., 2014). CFA has been shown the number of clinical, immunological and chronic feature similar to human arthritis. The primary reaction of the CFA showed the expansion of inflammation and developed the arthritic nodules in the tail and ear and persist the swelling in contralateral and showed the delayed response (secondary reaction). CFA induced RA rats showed the enhancement of paw joint in from day 3 and remain increase until 28 days. CFA control group rats showed the increase joint diameter till 28 days and suggest the delayed immunological flare in the RA disease (Kuroki et al., 2011; Wang et al., 2012).

Currently, available treatment for the arthritis is NSAIDS (Non-Steroidal Anti-Inflammatory Drugs) viz., indomethacin, aceclofenac, phenylbutazone, ibuprofen etc., DMARDs (Disease Modifying Anti-Rheumatic Drugs) viz., cyclosporin A, methotrexate etc, Anticytokine therapy such as infliximab, adalimumab etc and immune suppressive drugs are commonly used to control the inflammation and pain during arthritis (Kumar et al., 2016). Indomethacin is the first choice of the drug due to its specific action on COX and $\mathrm{PGE}_{2}$. But this drug has a limitation due to gastro intestinal irritation, diarrhea, rectal irritation, skin rash, hematologic toxicity and loss of response with chronic use (Kaithwas and Majumdar, 2010). It is moreover desirable that the more potent antiarthritic drugs be investigated for specific action on the inflammation and pain during arthritis.

During the arthritic condition, hematological parameters altered due to the expansion of disease. A similar result was observed in the CFA induced group rats. CFA group rats exhibited the increased level of ESR, WBC and reduced level of Hb RBC (Kumar et al., 2016). During the arthritic condition, the level of RBC and $\mathrm{Hb}$ decrease and create the anemia condition to the patient due to the deformability of erythrocyte (shorten the lifespan of erythrocyte). During the disease, the level of $\mathrm{Hb}$ was decreased due to the expansion of disease, resultant start the destruction of premature RBCs and reduction of erythropoietin (reduced the level of bone marrow erythropoietin) (Kumar et al., 2017). A similar condition was observed in our study. Another parameter such as WBC, its considers as the significant marker of the immune system which is linked with the induction of inflammation and its related other diseases. During the arthritic disease condition, IL-1 $\beta$ mediated WBC level increase and start the generation of colony stimulating factor, granulocyte and inflammatory macrophages (Jeyadevi et al., 2013). Crocetin significantly $(P<0.001)$ reduced the granulocytes and migration of inflammation macrophages at dose-dependent manner. Increased level of ESR start the generation of endogenous proteins and actively take part in the progression of the disease. Result suggests that the dosedependent treatment of crocetin altered the hematological condition near to the normal level and suggest the anti-arthritic effect.

Various researchers suggest that the hepatic parameters such as ALP, SGPT, and SGOT are the tool for the estimation of the anti-arthritic effect of the tested drug (Kumar et al., 2016). Serum SGPT and SGOT level played an important role in the formation of biologically active chemical mediators such as bradykinins in the inflammatory process and suggest a positive relation between the enhanced activity of serum ALP and RA activity (Kaithwas and Majumdar, 2010). The aminotransferases enzymes were significantly boosted in disease rats since there is the marker of kidney and liver impairment, which are also considered as the features of adjuvant arthritis (Gautam et al., 2016). During arthritis, the level of ALP increased in the bone fraction and liver or may be due to increasing the level of both isoenzymes. This in turn implicates a localized bone loss in the form of bone erosion and periarticularosteopenia, as the enzyme is released into circulation in the course of bone formation and resorption (Kaithwas and Majumdar, 2010). Concentration-dependent treatment of crocetin significantly decreased the activity of hepatic enzymes such as SGOT, SGPT, ALP and suggest the reduced the bone loss and provide the protection to the organ against adjuvant-induced arthritis in the rats. From the result, we can say that crocetin provided the anti-arthritic effect against the CFA induced arthritic rats due to alteration of biochemical parameters.

In the current experimental study, we scrutinized the macrophage-derived pro-inflammatory cytokines such as IL-6, TNF- $\alpha$, and IL- $1 \beta$. Various researchers suggested that the level of pro-inflammatory cytokines increase during the CFA induced RA (Qureshi et al., 2011). These cytokines boosted the local systemic inflammatory response and induced the cartilage, infiltration of immune cells and start the degradation of joint via degrading the enzymes such as metalloproteinases (MMPs) (Impellizzeri et al., 2012). For confirmation of the exact mechanism of action, in the current experimental study, we evaluated the pro-inflammatory cytokines in synovium and serum (Hübner et al., 1996; Fernandes et al., 2002; Kim et al., 2007; Neurath, 2014). The level of TNF- $\alpha$ was up-regulated in the arthritis patient. The up-regulated level of TNF- $\alpha$ start the damage of gastrointestinal at indomethacin group rats. CFA induced group rats showed the up-regulation of TNF- $\alpha$ and dose-dependent treatment of crocetin showed the down-regulation of pro-inflammatory cytokines level.

CFA induced control group rats showed that the rat's hind paw increased in diameter till the end of the experimental study. The increase in joint diameters increase is a result of arthritis disease (Hussein et al., 2012; Kumar et al., 2017). CFA induced group rats showed the reduced body weight and crocetin treatment showed the increased body weight and suggests the anti-arthritic effect. CFA induced showed the decreased body weight due to deficient absorption of nutrient via intestine and the treatment showed the increased body weight suggest the normalizing process of the intestine (Jalalpure et al., 2011; Nair et al., 2011; Suke et al., 2013; 
Jiang et al., 2014). The possible mechanism may be improved the level of nutrient from intestine absorption and down-regulation of distress induced through the severity of arthritis.

In the current investigation, the joint inflammation of crocetin treated group rats decreases at the end of the experimental study. CFA control rats showed the increased level of TNF- $\alpha$ and dose-dependent treatment of crocetin exhibited the reduction of TNF- $\alpha$, however, there was a higher TNF- $\alpha$ level was observed in the indomethacin group (Gautam et al., 2016). The increased level of TNF- $\alpha$ found in the indomethacin group due to gastrointestinal damage, which further caused the gastrointestinal ulcer. Inflammatory mediators such as IL-6, IL$1 \beta$, VEGF, and TNF-R1 are correlated with our finding in the animal investigation, as the expression of IL- 6 , IL- $1 \beta$, VEGF, and TNF-R1 were observed to be attenuated in the synovial membrane of crocetin and indomethacin group (De Groote et al., 1992; Stevens et al., 2008; Nadeau et al., 2011; Studer et al., 2011). Indomethacin was more effectual in reducing the joint inflammation via inhibiting the inflammatory mediators. The same results were observed in the crocetin group rats, which showed the reduction of joint inflammation and proinflammatory cytokines in a dose-dependent manner. The result suggests that crocetin preventing the destruction of joint and synovial membrane via the different/additional mechanism.

Various researchers suggest that pathogenesis of RA having various inflammatory reactions such as transcription factor, NF$\kappa \mathrm{B}$, which play a significant role in the joint degradation and inflammation via increased the expression of pro0inflammatory genes viz., IL-6, IL-1 $\beta$, TNF- $\alpha$, MMPs, and chemokines (Bonizzi and Karin, 2004; Shakibaei et al., 2007; Choi and Lee, 2010; Ali et al., 2011). The increased level of NF- $\kappa B$ in the synovial joint of animal and human during the RA is well observed. Now, the researcher focuses their research on the RA via inhibiting the NF$\kappa \mathrm{B}$ expression for the treatment of it. In the current investigation, we scrutinized the effect of NF- $\kappa \mathrm{B}$ in the control and treated group rats (Makó et al., 2010; Mori et al., 2011). Dose-dependent treatment of crocetin significantly $(P<0.001)$ decreased the expression of NF- $\mathrm{B}$ as compared to $\mathrm{CFA}$ induced rats. The current finding suggests that crocetin could be responsible for anti-arthritic activity via inhibition of NF- $\kappa \mathrm{B}$ expression.

$\mathrm{Nrf} 2$ is considered as the significant transcription factor which was found to numerous set of enzymes including GPx,

\section{REFERENCES}

Ali, S., Mohs, A., Thomas, M., Klare, J., Ross, R., Schmitz, M. L., et al. (2011). The dual function cytokine IL-33 interacts with the transcription factor NF- $\kappa \mathrm{B}$ to dampen NF- $\mathrm{B}$-stimulated gene transcription. J. Immunol. 187, 1609-1616. doi: 10.4049/jimmunol.100 3080

Bernardi, A., Zilberstein, A. C., Jäger, E., Campos, M. M., Morrone, F. B., Calixto, J. B., et al. (2009). Effects of indomethacin-loaded nanocapsules in experimental models of inflammation in rats. Br. J. Pharmacol. 158, 1104-1111. doi: 10.1111/j.1476-5381.2009. 00244.x

Bhalekar, M. R., Upadhaya, P. G., Nalawade, S. D., Madgulkar, A. R., and Kshirsagar, S. J. (2015). Anti-rheumatic activity of chloroquineSLN gel on wistar rats using complete freund's adjuvant (CFA) glutathione S-transferase and $\mathrm{HO}-1$ via binding of DNA sequence called antioxidant response element (ARE), which has the ability to reduced the pro-inflammatory pathway and antioxidant response (Itoh et al., 1999; Li et al., 2004; Jung and Kwak, 2010; Vomhof-DeKrey and Picklo, 2012). Various researchers suggest that cross relationship between NF-кB/IL-1 $\beta$ and Nrf2 and serve the joint destruction and oxidative injury in animals (Lee and Surh, 2005; Vomhof-DeKrey and Picklo, 2012). In the current experimental study, we have found that the crocetin treatment increased the mRNA expression of HO-1 and Nrf2 in CFA induced rats as compared to CFA control group rats and suggesting the suppression of oxidative stress and proinflammatory cytokines via altering the oxidative stress and pro-inflammatory cytokines level.

\section{CONCLUSION}

On the basis of the result, we can conclude that crocetin was an effective agent in attenuating the adjuvant-induced arthritis rats in a concentration-dependent manner, and therefore it could be scrutinized as a probable treatment for human chronic arthritis condition. The results suggest that crocetin is beneficial in the treatment of painful inflammatory and chronic arthritic condition. Additionally, particular identify the gene responsible for the anti-arthritic effect.

\section{AUTHOR CONTRIBUTIONS}

YL and RK performed the experimental study. JW, YL, and RK interpreted the biochemical data. All the authors equally contributed for the proofreading.

\section{FUNDING}

The current experimental study was supported by Key Research and Development Program of Shandong Province (No. 2017GSF18157) and Natural Science Foundation of Shandong Province (No. ZR2016HP39).

model. Indian J. Rheumatol. 10, 58-64. doi: 10.1016/j.injr.2015. 03.008

Bhandari, P. R. (2015). Crocus sativus L. (saffron) for cancer chemoprevention: A mini review. J. Tradit. Complement. Med. 5, 81-87. doi: 10.1016/j.jtcme.2014. 10.009

Boissier, M. C., Semerano, L., Challal, S., Saidenberg-Kermanac'h, N., and Falgarone, G. (2012). Rheumatoid arthritis: from autoimmunity to synovitis and joint destruction. J. Autoimmun. 39, 222-228. doi: 10.1016/j.jaut.2012. 05.021

Bonizzi, G., and Karin, M. (2004). The two NF-кB activation pathways and their role in innate and adaptive immunity. Trends Immunol. 25, 280-288. doi: 10.1016/j.it.2004.03.008

Bryan, N. S., and Grisham, M. B. (2007). Methods to detect nitric oxide and its metabolites in biological samples. Free Radic. Biol. Med. 43, 645-657. doi: 10.1016/j.freeradbiomed.2007.04.026 
Chen, L. G., Yang, L. L., and Wang, C. C. (2008). Anti-inflammatory activity of mangostins from Garcinia mangostana. Food Chem. Toxicol. 46, 688-693. doi: 10.1016/j.fct.2007.09.096

Choi, E. M., and Lee, Y. S. (2010). Luteolin suppresses IL-1 $\beta$-induced cytokines and MMPs production via $\mathrm{p} 38 \mathrm{MAPK}$, JNK, NF-kappaB and AP-1 activation in human synovial sarcoma cell line, SW982. Food Chem. Toxicol. 48, 2607-2611. doi: 10.1016/j.fct.2010.06.029

De Groote, D., Zangerle, P. F., Gevaert, Y., Fassotte, M. F., Beguin, Y., NoizatPirenne, F., et al. (1992). Direct stimulation of cytokines (IL-1 $\beta$, TNF- $\alpha$, IL-6, IL-2, IFN- $\gamma$ and GM-CSF) in whole blood. I. Comparison with isolated PBMC stimulation. Cytokine 4, 239-248. doi: 10.1016/1043-4666(92)90062-V

Eng, L. F., and Lee, Y. L. (2003). Response of chemokine antagonists to inflammation in injured spinal cord. Neurochem. Res. 28, 95-100. doi: 10.1023/ A:1021652229667

Esser, N., Legrand-Poels, S., Piette, J., Scheen, A. J., and Paquot, N. (2014). Inflammation as a link between obesity, metabolic syndrome and type 2 diabetes. Diabetes Res. Clin. Pract. 105, 141-150. doi: 10.1016/j.diabres.2014. 04.006

Fernandes, J. C., Martel-Pelletier, J., and Pelletier, J. P. (2002). The role of cytokines in osteoarthritis pathophysiology. Biorheology 39, 237-246. doi: 10.3233/BIR14016

Festuccia, C., Mancini, A., Gravina, G. L., Scarsella, L., Llorens, S., Alonso, G. L., et al. (2014). Antitumor effects of saffron-derived carotenoids in prostate cancer cell models. Bio. Med. Res. Int. 2014:135048. doi: 10.1155/2014/135048

Gautam, R., Singh, M., Gautam, S., Rawat, J. K., Saraf, S. A., and Kaithwas, G. (2016). Rutin attenuates intestinal toxicity induced by Methotrexate linked with anti-oxidative and anti-inflammatory effects. BMC Complement. Altern. Med. 16:99. doi: 10.1186/s12906-016-1069-1

Gutheil, W. G., Reed, G., Ray, A., Anant, S., and Dhar, A. (2012). Crocetin: an agent derived from saffron for prevention and therapy for cancer. Curr. Pharm. Biotechnol. 13, 173-179.

Gungor, H., Ilhan, N., and Ilhan, N. (2014). The effectiveness of cyclooxygenase-2 inhibitors and evaluation of angiogenesis in rat colorectal cancer model. Biomed Pharmacother. 102, 221-229.

Harford, K. A., Reynolds, C. M., McGillicuddy, F. C., and Roche, H. M. (2011). Fats, inflammation and insulin resistance: Insights to the role of macrophage and T-cell accumulation in adipose tissue. Proc. Nutr. Soc. 70, 408-417. doi: 10.1017/S0029665111000565

Heo, S. J., Yoon, W. J., Kim, K. N., Ahn, G. N., Kang, S. M., Kang, D. H., et al. (2010). Evaluation of anti-inflammatory effect of fucoxanthin isolated from brown algae in lipopolysaccharide-stimulated RAW 264.7 macrophages. Food Chem. Toxicol. 48, 2045-2051. doi: 10.1016/j.fct.2010.05.003

Heo, S. J., Yoon, W. J., Kim, K. N., Oh, C., Choi, Y. U., Yoon, K. T., et al. (2012). Anti-inflammatory effect of fucoxanthin derivatives isolated from Sargassum siliquastrum in lipopolysaccharide-stimulated RAW 264.7 macrophage. Food Chem. Toxicol. 50, 3336-3342. doi: 10.1016/j.fct.2012.06.025

Hseu, Y. C., Wu, F. Y., Wu, J. J., Chen, J. Y., Chang, W. H., Lu, F. J., et al. (2005). Anti-inflammatory potential of antrodia camphorata through inhibition of iNOS, COX-2 and cytokines via the NF-кB pathway. Int. Immunopharmacol. 5, 1914-1925. doi: 10.1016/j.intimp.2005.06.013

Hübner, G., Brauchle, M., Smola, H., Madlener, M., Fässler, R., and Werner, S. (1996). Differential regulation of pro-inflammatory cytokines during wound healing in normal and glucocorticoid-treated mice. Cytokine 8, 548-556. doi: 10.1006/cyto.1996.0074

Hussein, S. Z., Mohd Yusoff, K., Makpol, S., and Mohd Yusof, Y. A. (2012). Gelam honey inhibits the production of proinflammatory, mediators NO, PGE 2, TNF- $\alpha$, and IL-6 in carrageenan-induced acute paw edema in rats. Evid. Based Complement. Altern. Med. 2012:109636. doi: 10.1155/2012/10 9636

Impellizzeri, D., Esposito, E., Mazzon, E., Paterniti, I., Di Paola, R., Bramanti, P., et al. (2012). The effects of a polyphenol present in olive oil, oleuropein aglycone, in an experimental model of spinal cord injury in mice. Biochem. Pharmacol. 83, 1413-1426. doi: 10.1016/j.bcp.2012. 02.001

Itoh, K., Wakabayashi, N., Katoh, Y., Ishii, T., Igarashi, K., Engel, J. D., et al. (1999). Keap1 represses nuclear activation of antioxidant responsive elements by Nrf2 through binding to the amino-terminal Neh2 domain. Genes Dev. 13, 76-86. doi: $10.1101 / \mathrm{gad} \cdot 13.1 .76$
Jalalpure, S. S., Mandavkar, Y. D., Khalure, P. R., Shinde, G. S., Shelar, P. A., and Shah, A. S. (2011). Antiarthritic activity of various extracts of Mesua ferrea Linn. seed. J. Ethnopharmacol. 138, 700-704. doi: 10.1016/j.jep.2011. 09.042

Jeyadevi, R., Sivasudha, T., Rameshkumar, A., and Kumar, L. D. (2013). An antiarthritic activity of the Indian leafy vegetable Cardiospermum halicacabum in wistar rats and UPLC-QTOF- MS/MS identification of the putative active phenolic components. Inflamm. Res. 62, 115-126. doi: 10.1007/s00011-0120558-z

Jiang, L., Li, W., Wang, Y., Zhang, X., Yu, D., Yin, Y., et al. (2014). Effects of cichoric acid extract from Echinacea purpurea on collagen-induced arthritis in rats. Am. J. Chin. Med. 42, 679-692. doi: 10.1142/S0192415X1450044X

Jimenez-Boj, E., Redlich, K., Turk, B., Hanslik-Schnabel, B., Wanivenhaus, A., Chott, A., et al. (2005). Interaction between synovial inflammatory tissue and bone marrow in rheumatoid arthritis. J. Immunol. 175, 2579-2588. doi: 10. 4049/jimmunol.175.4.2579

Jung, K. A., and Kwak, M. K. (2010). The Nrf2 system as a potential target for the development of indirect antioxidants. Molecules 15, 7266-7291. doi: 10.3390/ molecules 15107266

Kaithwas, G., Gautam, R., Jachak, S. M., and Saklani, A. (2012). Antiarthritic effects of Ajuga bracteosa wall ex benth. In acute and chronic models of arthritis in albino rats. Asian Pac. J. Trop. Biomed. 2, 185-188. doi: 10.1016/S2221-1691(12) 60039-2

Kaithwas, G., and Majumdar, D. K. (2010). Therapeutic effect of Linum usitatissimum (flaxseed/linseed) fixed oil on acute and chronic arthritic models in albino rats. Inflammopharmacology 18, 127-136. doi: 10.1007/s10787-0100033-9

Kasimanickam, V. R., Kasimanickam, R. K., and Dernell, W. S. (2014). Dysregulated microRNA clusters in response to retinoic acid and CYP26B1 inhibitor induced testicular function in dogs. PLoS One 9:e99433. doi: 10.1371/ journal.pone.0099433

Kaur, S., White, S., and Bartold, M. (2012). Periodontal disease as a risk factor for rheumatoid arthritis: a systematic review. JBI Libr. Syst. Rev. 42(Suppl.), 1-12. doi: 10.11124/jbisrir-2012-288

Kim, Y. K., Jung, H. G., Myint, A. M., Kim, H., and Park, S. H. (2007). Imbalance between pro-inflammatory and anti-inflammatory cytokines in bipolar disorder. J. Affect. Disord. 104, 91-95. doi: 10.1016/j.jad.2007.02.018

Kmieć, Z. (2001). Cooperation of liver cells in health and disease. Adv. Anat. Embryol. Cell Biol. III-XIII, 1-151. doi: 10.1007/978-3-642-56553-3

Kumar, R., Nair, V., Gupta, Y. K., and Singh, S. (2017). Anti-inflammatory and anti-arthritic activity of aqueous extract of Rosa centifolia in experimental rat models. Int. J. Rheum. Dis. 20, 1072-1078. doi: 10.1111/1756-185X.12625

Kumar, V., Al-Abbasi, F. A., Verma, A., Mujeeb, M., and Anwar, F. (2015). Umbelliferone $\beta$-d-galactopyranoside exerts an anti-inflammatory effect by attenuating COX-1 and COX-2. Toxicol. Res. (Camb). 4, 1072-1084. doi: 10. 1039/c5tx90017d

Kumar, V., Bhatt, P. C., Rahman, M., Patel, D. K., Sethi, N., Kumar, A., et al. (2016). Melastoma malabathricum Linn attenuates complete freund's adjuvantinduced chronic inflammation in Wistar rats via inflammation response. BMC Complement. Altern. Med. 16:510. doi: 10.1186/s12906-016-1470-9

Kuroki, Y., Honda, K., Kijima, N., Wada, T., Arai, Y., Matsumoto, N., et al. (2011). In vivo morphometric analysis of inflammatory condylar changes in rat temporomandibular joint. Oral Dis. 17, 499-507. doi: 10.1111/j.1601-0825. 2010.01782.x

Lee, J. S., and Surh, Y. J. (2005). Nrf2 as a novel molecular target for chemoprevention. Cancer Lett. 224, 171-184. doi: 10.1016/j.canlet.2004.09.042

Li, N., Alam, J., Venkatesan, M. I., Eiguren-Fernandez, A., Schmitz, D., Di Stefano, E., et al. (2004). Nrf2 is a key transcription factor that regulates antioxidant defense in macrophages and epithelial cells: protecting against the proinflammatory and oxidizing effects of diesel exhaust chemicals. J. Immunol. 173, 3467-3481. doi: 10.4049/jimmunol.173.5.3467

Makó, V., Czúcz, J., Weiszhár, Z., Herczenik, E., Matkó, J., Prohászka, Z., et al. (2010). Proinflammatory activation pattern of human umbilical vein endothelial cells induced by IL-1 $\beta$, TNF- $\alpha$, and LPS. Cytom. Part A 77, 962-970. doi: $10.1002 /$ cyto.a.20952

Martel-Pelletier, J., Boileau, C., Pelletier, J. P., and Roughley, P. J. (2008). Cartilage in normal and osteoarthritis conditions. Best Pract. Res. Clin. Rheumatol. 22, 351-384. doi: 10.1016/j.berh.2008.02.001 
Mori, T., Miyamoto, T., Yoshida, H., Asakawa, M., Kawasumi, M., Kobayashi, T., et al. (2011). IL-1 $\beta$ and TNF $\alpha$-initiated IL-6-STAT3 pathway is critical in mediating inflammatory cytokines and RANKL expression in inflammatory arthritis. Int. Immunol. 23, 701-712. doi: 10.1093/intimm/dxr077

Nadeau, S., Filali, M., Zhang, J., Kerr, B. J., Rivest, S., Soulet, D., et al. (2011). Functional recovery after peripheral nerve injury is dependent on the pro-inflammatory cytokines IL-1 and TNF: implications for neuropathic pain. J. Neurosci. 31, 12533-12542. doi: 10.1523/JNEUROSCI.284011.2011

Nair, V., Singh, S., and Gupta, Y. K. (2011). Evaluation of the disease modifying activity of colchicum luteum Baker in experimental arthritis. J. Ethnopharmacol. 133, 303-307. doi: 10.1016/j.jep.2010.09.027

Neurath, M. F. (2014). Cytokines in inflammatory bowel disease. Nat. Rev. Immunol. 14, 329-342. doi: 10.1038/nri3661

Ohgami, K., Shiratori, K., Kotake, S., Nishida, T., Mizuki, N., Yazawa, K., et al. (2003). Effects of astaxanthin on lipopolysaccharide-induced inflammation in vitro and in vivo. Investig. Ophthalmol. Vis. Sci. 44, 2694-2701. doi: 10.1167/ iovs.02-0822

Pahan, K., Sheikh, F. G., Namboodiri, A. M. S., and Singh, I. (1998). $\mathrm{N}$-acetyl cysteine inhibits induction of no production by endotoxin or cytokine stimulated rat peritoneal macrophages, C6 glial cells and astrocytes. Free Radic. Biol. Med. 24, 39-48. doi: 10.1016/S0891-5849(97)0 0137-8

Park, H. H., Kim, M. J., Li, Y., Park, Y. N., Lee, J., Lee, Y. J., et al. (2013). Britanin suppresses LPS-induced nitric oxide, PGE2and cytokine production via NF$\mathrm{\kappa B}$ and MAPK inactivation in RAW 264.7 cells. Int. Immunopharmacol. 15, 296-302. doi: 10.1016/j.intimp.2012.12.005

Qureshi, A. A., Tan, X., Reis, J. C., Badr, M. Z., Papasian, C. J., Morrison, D. C., et al. (2011). Suppression of nitric oxide induction and pro-inflammatory cytokines by novel proteasome inhibitors in various experimental models. Lipids Health Dis. 10:177. doi: 10.1186/1476-511X-10-177

Rahman, I. (2002). Oxidative stress, transcription factors and chromatin remodelling in lung inflammation. Biochem. Pharmacol. 64, 935-942. doi: 10. 1016/S0006-2952(02)01153-X

Randell, A., and Daneshtalab, N. (2016). Adjuvant-induced mono-arthritis potentiates cerebral hemorrhage in the spontaneously hypertensive rats. Life Sci. 151, 15-22. doi: 10.1016/j.lfs.2016.02.012

Rayhana, B., Sheliya, M. A., Pillai, K. K., Aeri, V., and Sharma, M. (2014). Evaluation of anti-inflammatory effect of Careya arborea in CFA induced chronic inflammation. Int. J. Pharm. Sci. Rev. Res. 26, 292-298.

Sahoo, N., Manchikanti, P., and Dey, S. (2010). Herbal drugs: standards and regulation. Fitoterapia 81, 462-471. doi: 10.1016/j.fitote.2010.02.001

Scott, D. L., Wolfe, F., and Huizinga, T. W. J. (2010). Rheumatoid arthritis. Lancet 376, 1094-1108. doi: 10.1016/S0140-6736(10)60826-4

Scutellari, P. N., and Orzincolo, C. (1998). Rheumatoid arthritis: Sequences. Eur. J. Radiol. 1:S31-8. doi: 10.1016/S0720-048X(98)00040-0

Sellam, J., and Berenbaum, F. (2010). The role of synovitis in pathophysiology and clinical symptoms of osteoarthritis. Nat. Rev. Rheumatol. 6, 625-635. doi: 10.1038/nrrheum.2010.159

Shakibaei, M., John, T., Schulze-Tanzil, G., Lehmann, I., and Mobasheri, A. (2007). Suppression of NF- $\mathrm{B}$ activation by curcumin leads to inhibition of expression of cyclo-oxygenase- 2 and matrix metalloproteinase- 9 in human articular chondrocytes: implications for the treatment of osteoarthritis. Biochem. Pharmacol. 73, 1434-1445. doi: 10.1016/j.bcp.2007.01.005

Sindhu, G., Ratheesh, M., Shyni, G. L., Nambisan, B., and Helen, A. (2012). Anti-inflammatory and antioxidative effects of mucilage of Trigonella foenum graecum (Fenugreek) on adjuvant induced arthritic rats. Int. Immunopharmacol. 12, 205-211. doi: 10.1016/j.intimp.2011. 11.012

Stevens, A. L., Wheeler, C. A., Tannenbaum, S. R., and Grodzinsky, A. J. (2008). Nitric oxide enhances aggrecan degradation by aggrecanase in response to TNF- $\alpha$ but not IL-1 $\beta$ treatment at a post-transcriptional level in bovine cartilage explants. Osteoarthr. Cartil. 16, 489-497. doi: 10.1016/j.joca.2007. 07.015

Studer, R. K., Vo, N., Sowa, G., Ondeck, C., and Kang, J. (2011). Human nucleus pulposus cells react to IL-6: independent actions and amplification of response to IL-1 and TNF- $\alpha$. Spine (Phila. Pa. 1976) 36, 593-599. doi: 10.1097/BRS. 0b013e3181da38d5

Suke, S. G., Negi, H., Mediratta, P. K., Banerjee, B. D., and Sharma, K. K. (2013). Anti-arthritic and anti-inflammatory activity of combined pioglitazone and prednisolone on adjuvant-induced arthritis. Eur. J. Pharmacol. 718, 57-62. doi: 10.1016/j.ejphar.2013.09.019

Tekieh, E., Akbari, A., Manaheji, H., Rezazadeh, S., and Zaringhalam, J. (2011). Anti-hyperalgesic and anti-inflammatory effects of achillea santolina and stachys athorecalyx extracts on complete freund's adjuvant-induced short-term inflammation in male wistar rats. Koomesh 12, 305-3313.

Vomhof-DeKrey, E. E., and Picklo, M. J. (2012). The Nrf2-antioxidant response element pathway: a target for regulating energy metabolism. J. Nutr. Biochem. 23, 1201-1206. doi: 10.1016/j.jnutbio.2012.03.005

Walsh, D. A., and McWilliams, D. F. (2012). Pain in rheumatoid arthritis. Curr. Pain Headache Rep. 16, 509-517. doi: 10.1007/s11916-012-0303-x

Wang, X. D., Kou, X. X., Mao, J. J., Gan, Y. H., and Zhou, Y. H. (2012). Sustained inflammation induces degeneration of the temporomandibular joint. J. Dent. Res. 91, 499-505. doi: 10.1177/0022034512441946

Xu, H., Barnes, G. T., Yang, Q., Tan, G., Yang, D., Chou, C. J., et al. (2003). Chronic inflammation in fat plays a crucial role in the development of obesityrelated insulin resistance. J. Clin. Invest. 112, 1821-1830. doi: 10.1172/JCI 19451

Yoon, W.-J., Ham, Y. M., Kim, S.-S., Yoo, B.-S., Moon, J.-Y., Baik, J. S., et al. (2009). Suppression of pro-inflammatory cytokines, iNOS, and COX-2 expression by brown algae Sargassum micracanthum in RAW 264.7 macrophages. Eur Asian J. Biosci. 143, 130-143. doi: 10.5053/ejobios.2009.3.0.17

Zhang, G., Lin, X., Zhang, S., Xiu, H., Pan, C., and Cui, W. A. (2017). Protective Role of Glibenclamide in Inflammation-Associated Injury. Med. Inflamm. 2017:3578702. doi: 10.1155/2017/3578702

Zhang, Y., Leung, D. Y. M., Richers, B. N., Liu, Y., Remigio, L. K., Riches, D. W., et al. (2012). Vitamin D inhibits monocyte/macrophage proinflammatory cytokine production by targeting MAPK phosphatase-1. J. Immunol. 188, 2127-2123. doi: 10.4049/jimmunol.1102412

Zong, Y., Sun, L., Liu, B., Deng, Y. S., Zhan, D., Chen, Y. L., et al. (2012). Resveratrol inhibits LPS-induced MAPKs activation via activation of the phosphatidylinositol 3-kinase pathway in murine RAW 264.7 macrophage Cells. PLoS One 7:e44107. doi: 10.1371/journal.pone.0044107

Conflict of Interest Statement: The authors declare that the research was conducted in the absence of any commercial or financial relationships that could be construed as a potential conflict of interest.

Copyright (C) 2018 Li, Kakkar and Wang. This is an open-access article distributed under the terms of the Creative Commons Attribution License (CC BY). The use, distribution or reproduction in other forums is permitted, provided the original author(s) and the copyright owner(s) are credited and that the original publication in this journal is cited, in accordance with accepted academic practice. No use, distribution or reproduction is permitted which does not comply with these terms. 